FRANCHI, G.A. et al. Percepção do mercado consumidor de Piracicaba em relação ao bemestar dos animais de produção. PUBVET, Londrina, V. 6, N. 11, Ed. 198, Art. 1325, 2012.

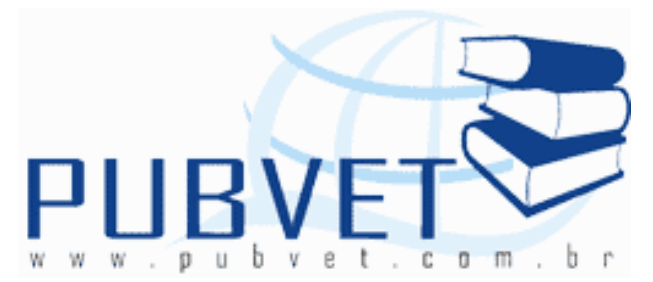

PUBVET, Publicações em Medicina Veterinária e Zootecnia.

\title{
Percepção do mercado consumidor de Piracicaba em relação ao bem- estar dos animais de produção
}

\author{
Guilherme Amorim Franchi ${ }^{1}$, Maria Luísa Appendino Nunes ${ }^{2}$, \\ Paulo Rogério Garcia ${ }^{3}$, Iran José Oliveira da Silva ${ }^{4}$
}

${ }^{1}$ Graduando em Engenharia Agronômica (ESALQ/USP) e pesquisador do Núcleo de Pesquisa em Ambiência (NUPEA/ESALQ/USP).

2 Professora do Curso de Zootecnia da Universidade do Estado de Santa Catarina (UDESC), em Chapecó-SC. Atualmente afastada para o doutoramento junto ao NUPEA/ESALQ.

${ }^{3}$ Biológo - Bacharel em Ciëncias Biológicas, ESALQ/USP - 2010. Mestrando NUPEA/ESALQ/USP.

4 Professor Doutor da Escola Superior de Agricultura Luiz de Queiroz ESALQ/USP e coordenador do Núcleo de Pesquisa em Ambiência (NUPEA/ESALQ/USP).

\section{Resumo}

A desinformação da sociedade com relação aos animais de produção tem sido um fator limitante para a implantação do conceito de bem-estar aplicado a esta categoria animal. Por meio deste trabalho, objetivou-se identificar a percepção do público consumidor a respeito do conceito de bem-estar de animais de produção (BEAP), assim como identificar quais são os fatores considerados na escolha de um produto de origem animal. Para tanto, aplicou- 
FRANCHI, G.A. et al. Percepção do mercado consumidor de Piracicaba em relação ao bemestar dos animais de produção. PUBVET, Londrina, V. 6, N. 11, Ed. 198, Art. 1325, 2012.

se um questionário, contemplando as seguintes informações: características consideradas na compra de produtos de origem animal, conhecimento quanto à sensciência animal e opinião quanto ao interesse da sociedade a respeito do tema. Os entrevistados foram identificados quanto à idade, sexo, renda e consumo de produtos de origem animal. Foram aplicados 493 questionários, no Município de Piracicaba/SP e os resultados foram analisados por meio de estatística descritiva. Com relação ao perfil dos entrevistados, constatou-se uma predominância do público feminino nos supermercados $(65 \%)$. Além disso, 36,9\% do público entrevistado tinham idade entre 41 e 60 anos. Do total, $98 \%$ revelaram consumir produtos de origem animal. Com relação ao conhecimento sobre BEAP e à tomada de decisão em função do mesmo, 60,4\% dos entrevistados responderam que não leva em consideração o BEAP no ato da compra. Entretanto, $91,5 \%$ dos entrevistados acreditam que os animais possuem sentimentos. Os sentimentos mais atribuídos aos animais foram: dor, $89,2 \%$; medo, $86,6 \%$ e alegria, $68,6 \%$. Da totalidade dos entrevistados, $52 \%$ acreditam que o BEAP é um assunto de interesse da sociedade. Por fim, as características consideradas no ato da compra e consumo de produtos de origem animal pelos entrevistados foram: qualidade, preço e validade. Percebe-se que, ao mesmo tempo em que as pessoas consideram a senciência, a tomada de decisão quanto ao tema é incipiente. A difusão de conhecimentos com relação ao bem-estar dos animais de produção, bem como sobre questões relacionadas à cadeia produtiva podem contribuir para a preparação da sociedade no sentido do consumo ético.

Palavras-chave: Animal, bem-estar, consumo, interesse, atitude 
FRANCHI, G.A. et al. Percepção do mercado consumidor de Piracicaba em relação ao bemestar dos animais de produção. PUBVET, Londrina, V. 6, N. 11, Ed. 198, Art. 1325, 2012.

\title{
Perception of consumer market towards the welfare of production animals in Piracicaba, Sao Paulo, Brazil
}

\begin{abstract}
The lack of information of the society in relation to livestock welfare has been a limiting factor for the implementation of the "livestock welfare" concept and ethical consumption. This study aimed to identify the consumer's consciousness about this concept and what factors are considered when choosing the final livestock product. To obtain the data, a questionnaire was developed, contemplating the following information: characteristics taken into account when buying animal origin products, knowledge of the interviewee about the animal's consciousness and the opinion about the society's interesting in animal welfare. To identify the interviewee, data were collected regarding age, gender, income and consumption of livestock products. Questionnaires were administered to 493 people at two establishments in the city of Piracicaba and the results were analyzed by descriptive statistics, through the Excel program. With regard to the profile of the interviewees, it is possible to note a predominance of female public in supermarkets, $65 \%$ versus $35 \%$ of men. In addition, $36.9 \%$ of the public interviewed were aged between 41 and 60 . Of the total, $98 \%$ reported consuming livestock products. In relation to the knowledge of the production animal welfare and decision-making function of the same, $60.4 \%$ of the interviewees answered that they do not take into account the welfare of livestock animals at the time of purchase. However, $91.5 \%$ of the interviewees believe that animals have feelings. The feelings were attributed to animal: pain, 89.2\%; fear, $86,6 \%$; and joy, $68,6 \%$. Of all interviewees, $52 \%$ believe the BEAP is a subject of society's concern. Finally, the characteristics considered in the purchase and consumption of livestock products by interviewees were: quality, price and date. Therefore, it is possible to ensure that there is a distinct lack of knowledge about the
\end{abstract}


FRANCHI, G.A. et al. Percepção do mercado consumidor de Piracicaba em relação ao bemestar dos animais de produção. PUBVET, Londrina, V. 6, N. 11, Ed. 198, Art. 1325, 2012.

welfare of production animals as well as the processes involved in the production chain. It also found that there is little contact of people, in general, with farm animals.

Keywords: Animal, welfare, consumption, interest, attitude

\section{Introdução}

Devido à crescente demanda por alimentos registrada nos últimos tempos, principalmente os de origem animal, os sistemas de produção se intensificam mais e mais, a fim de buscar suprir o consumo e melhorar a qualidade dos produtos comercializados. Entretanto, não é apenas a qualidade, ou aspecto, de um determinado produto de origem animal, que é levado em consideração no ato da compra. Principalmente nos países desenvolvidos, questões relacionadas à segurança alimentar, sanitária e ao consumo ético, têm sido, corriqueiramente, consideradas pela população. Esta, de posse de uma grande variedade de fontes de informação, busca, constantemente, ter conhecimento dos meios de produção pelos quais passou o produto que será consumido.

A realidade brasileira é diferente daquela vista nos países de 10 mundo. Ainda são poucos e incipientes os programas de conscientização da população a respeito de questões como bem-estar animal ou consumo ético. Mesmo assim percebe-se uma mudança de hábitos e conceitos cada vez maior sobre esse tema por uma parcela crescente da população. Um exemplo disso é a crescente oferta e demanda por produtos orgânicos e certificados. Tais fatos levam, portanto, à necessidade de um levantamento quanti-qualitativo do perfil dos consumidores em relação a temáticas que no futuro próximo serão parâmetros de tomada de decisão na produção e no consumo dos alimentos, como por exemplo, o bem-estar dos animais de produção, (BEAP). 
FRANCHI, G.A. et al. Percepção do mercado consumidor de Piracicaba em relação ao bemestar dos animais de produção. PUBVET, Londrina, V. 6, N. 11, Ed. 198, Art. 1325, 2012.

\section{Objetivo}

O objetivo geral da pesquisa foi o de identificar, por meio de um levantamento quanti-qualitativo, a percepção do público consumidor com relação ao conceito de bem-estar de animais de produção, assim como identificar quais são os fatores considerados na escolha do produto final.

\section{Desenvolvimento Teórico}

Das muitas definições propostas para Bem-Estar, a mais aceita no ambiente científico é aquela publicada por BROOM (1986), segundo a qual "bem-estar de um indivíduo é seu estado em relação às suas tentativas de lidar com o ambiente". No caso dos animais, enfocar o grau de dificuldade que um animal demonstra na sua interação com o ambiente é uma forma de por esse conceito em prática. Além disso, é preciso considerar o conceito de senciência animal, a qual é a capacidade de os animais apresentarem respostas e sentimentos a uma determinada situação, semelhantemente aos seres humanos, como alegria, frustração e medo, dentre outros (WSPA).

Além disso, é preciso ressaltar os tipos de alimentação e suas consequências para o meio ambiente. $O$ primeiro tipo é a dieta padrão norteamericana, que é forte e rica em carne, laticínios e ovos, a maioria proveniente de granjas industriais. A segunda é chamada de "onívorosconsciente", ou seja, os adeptos comem carne, assim como laticínios e ovos, mas tentam achar fontes mais éticas desses produtos, então compram alimentos orgânicos, ou com "certificados de humanidade". E a terceira família é a de "veganos", estritos, os quais não comem nenhum produto animal (Singer, 2002). É claro que a primeira dieta é a mais desastrosa para o meio ambiente e para os animais, os quais, na maioria dos casos, passam por fortes processos artificiais de produção. Já os outros dois tipos causam os menores impactos ao meio ambiente. Segundo Singer, a base ética no que concerne aos animais é a consideração igualitária de interesses e uma rejeição do "especiecismo", ou 
FRANCHI, G.A. et al. Percepção do mercado consumidor de Piracicaba em relação ao bemestar dos animais de produção. PUBVET, Londrina, V. 6, N. 11, Ed. 198, Art. 1325, 2012.

seja, a idéia de que simplesmente porque alguns seres não são membros de nossa espécie podemos negligenciar ou ignorar seus interesses.

Também é possível ver numa mesma sociedade indivíduos que se enquadram em extremos opostos quanto às suas prioridades na relação ser humano-animal. Porém, ocorrem situações nas quais existe coincidência entre as prioridades dos seres humanos sobre a manutenção de um grau aceitável de bem-estar para os animais (MOLENTO, 2005). O conhecimento sobre o modo de pensar e agir da maioria das pessoas de uma determinada sociedade é vital para o acerto na tomada de decisões. Isso traria melhoria gradativa das condições de BEA, bem como para auxiliar os profissionais no delineamento de projetos educacionais e na extensão do BEA.

Nesse sentido, em pesquisa realizada por Molento et al.(2006), com o intuito de conhecer a percepção e a atitude da população curitibana em relação ao grau de sofrimento a que os animais de produção estão submetidos nas diferentes cadeias produtivas, foi possível visualizar que o conhecimento da população estudada com relação ao grau de sofrimento dos animais de produção é escasso. Já que apenas $37,7 \%$ e $27,7 \%$ dos pesquisados consideraram sofrimento pequeno para bovinos de leite e galinhas poedeiras, e apenas $31,6 \%, 32,1 \%$ e $35,7 \%$ acreditam num elevado nível de sofrimento para sistemas de bovinos de corte, frangos de corte e suínos, respectivamente.

Percebe-se que no cenário de produção animal existe falta de conhecimento da população acerca dos procedimentos envolvidos. Uma sociedade mais informada poderia tomar decisões diferenciadas em relação à forma de manutenção de animais de produção, potencialmente gerando nichos de mercado e incentivando a melhoria da qualidade dos produtos (Lensink et al.2001).

\section{Material e Métodos}

A pesquisa de opinião foi conduzida por pesquisadores do Núcleo de Pesquisa em Ambiência (NUPEA/ESALQ/USP), entre os dias 18 e 26 de janeiro 
FRANCHI, G.A. et al. Percepção do mercado consumidor de Piracicaba em relação ao bemestar dos animais de produção. PUBVET, Londrina, V. 6, N. 11, Ed. 198, Art. 1325, 2012.

de 2011, em dois estabelecimentos comerciais na cidade de Piracicaba, São Paulo. Tais estabelecimentos comerciais (supermercados) foram selecionados sob dois aspectos, grande porte (estabelecimento A), com área aproximada de $8000 \mathrm{~m}^{2}$ e médio porte (estabelecimento B), com área aproximada de 2500 $\mathrm{m}^{2}$.

O levantamento quanti-qualitativo foi realizado simultaneamente nos dois estabelecimentos, sendo aplicados durante duas horas no período matutino e duas horas no período vespertino. A abordagem realizada pelos pesquisadores foi realizada na parte externa dos estabelecimentos, sendo escolhidos aleatoriamente os entrevistados que entravam e saiam do local. Durante esse período foram entrevistadas 493 pessoas.

A metodologia aplicada para o registro dos dados foi por meio de um questionário padrão, de acordo com o quadro 01 abaixo:

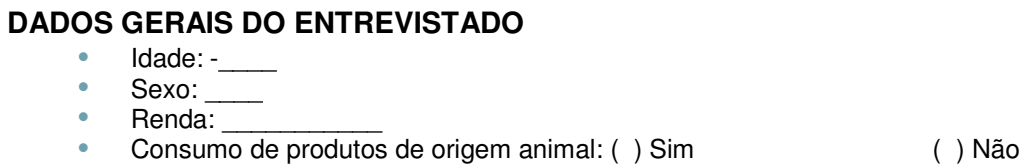

ATITUDES QUANTO AO CONSUMO DE PRODUTOS DE ORIGEM ANIMAL (apenasaos consumidores de produtos de origem animal)

- Quais os pontos você leva em consideræ̧ão quando compra e consome produtos de origem animal?

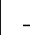

- Ao escolher por diferentes produtos de origem animal, você rea liza algum tipo de opção em função do bem-estar animal?

$\begin{array}{ll}\text { ( ) } \operatorname{Sim} & \text { ( ) Não }\end{array}$

PERCEP ÇÃO SOBRE BEM -ESTAR ANIMAL

- Você acredita que os animais possuem algum tipo de sentimento? (Senciência Animal)

( ) Sim ( ) Não

- Dos sentimentos listados abaixo, qual(is) você considera que os animais possuem?

( ) Dor ( ) Alegria

( ) Medo ( ) Angústia

( ) Frustração ( ) Outro. Especificar:

- Você acredita que o bem-estar animal é um assunto de interesse na nossa sociedade?

( ) Sim ( ) Não

Quadro 01 - Modelo do levantamento quanti -qualitativo aplicado aos consumidores 
FRANCHI, G.A. et al. Percepção do mercado consumidor de Piracicaba em relação ao bemestar dos animais de produção. PUBVET, Londrina, V. 6, N. 11, Ed. 198, Art. 1325, 2012.

A análise dos resultados foi realizada por meio da tabulação das informações pelo Excel e aplicado as respectivas percentagens nas questões envolvidas no levantamento.

\section{Resultados:}

A análise de caracterização do perfil do consumidor durante essa pesquisa de campo pode ser observada nas figuras 1 e 2 , e na tabela 1.

É possível visualizar que ocorre uma predominância do público feminino nos supermercados, $65 \%$, enquanto que os homens representam apenas 35 \%. Isso também foi constatado durante uma pesquisa semelhante realizada por Molento et al(2006)., no município de Curitiba, PR, na qual computou-se $62,5 \%$ de mulheres e $37,6 \%$ de homens.

Esses resultados são reflexos da atual conjuntura social e da situação do mercado consumidor brasileiro. Segundo o Censo 2010, realizado pelo IBGE, existem aproximadamente 97 milhões de mulheres no Brasil, contra 93 milhões de homens. Além disso, as decisões de compra nas famílias estão cada vez mais nas mãos das mulheres. De acordo com dados da Fundação Sistema Estadual de Análise de Dados do Estado de São Paulo, em 2011, as mulheres representam 43,3 \% da população economicamente ativa do estado de São Paulo. Este resultado não difere daquele apresentado pelo IBGE, de 44 \%. Além disso, de acordo com o IBGE, as mulheres também são as responsáveis financeiras por 31\% dos domicílios brasileiros, ante 19\% em 1991.

Uma das diferenças entre os dados de Molento (2006) e os obtidos por esse levantamento refere-se à faixa etária predominante. Nos dados de Molento (2006), 34,5 \% dos pesquisados foram da faixa etária entre 19 e 25 anos. Enquanto que nesse levantamento, a maior parte dos entrevistados, ou $36,9 \%$, tinha idade entre 41 e 60 anos.

Tal resultado encontrado no levantamento feito em Piracicaba ilustra mais uma mudança que está ocorrendo no perfil dos consumidores brasileiros. Atualmente, o contingente de pessoas com mais de 60 anos ultrapassa 21 
FRANCHI, G.A. et al. Percepção do mercado consumidor de Piracicaba em relação ao bemestar dos animais de produção. PUBVET, Londrina, V. 6, N. 11, Ed. 198, Art. 1325, 2012.

milhões (PNAD 2008) - número que supera a população da terceira idade em países como França, Inglaterra e Itália. No Brasil, os maiores de 75 anos já são 5,5 milhões. De 1998 a 2008, a proporção de idosos na população nacional aumentou de $8,8 \%$ para $11,1 \%$, sendo que o número de paulistanos com mais de 60 anos subiu 35\%, chegando a 1,3 milhão (IBGE 2010).

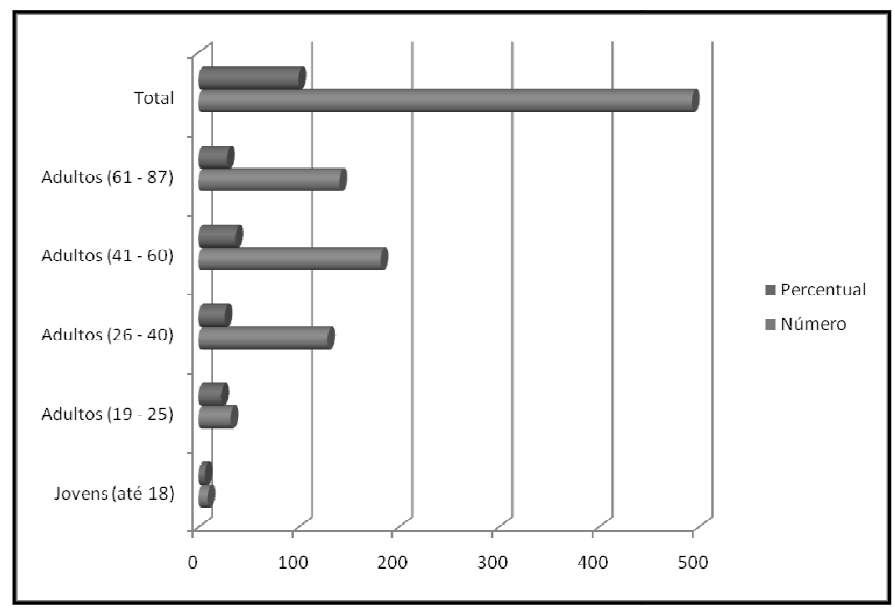

Figura 1: Porcentagem total de homens e mulheres de ambos os mercados.

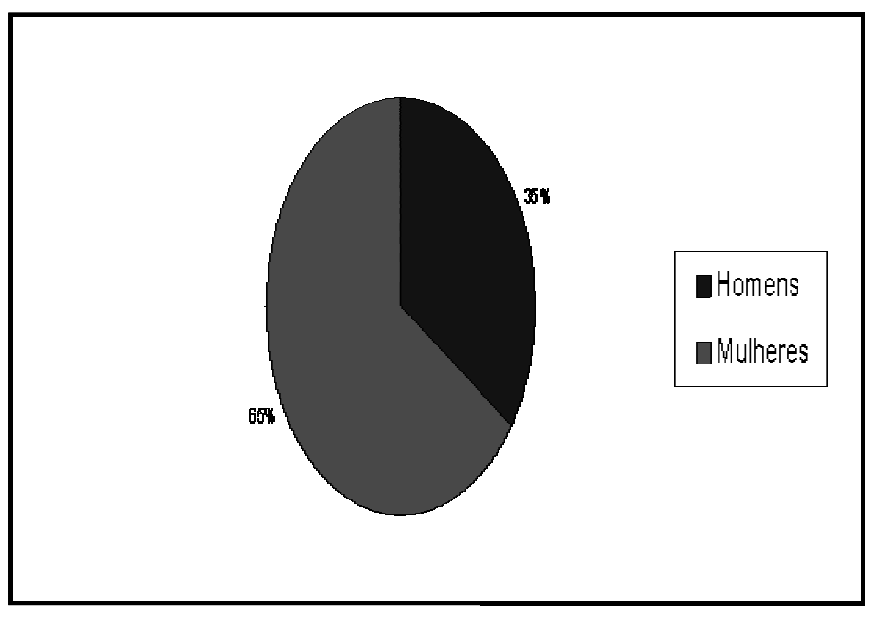

Figura 2: Distribuição geral da faixa etária dos entrevistados

Tabela 1: Porcentagem de homens e mulheres em cada estabelecimento.

\section{Homens}

Estabelecimento A

Estabelecimento B
$37,8 \%$

$31 \%$
Mulheres

$62,2 \%$

$69 \%$
Total

$100 \%$

$100 \%$

A porcentagem de consumidores de produtos de origem animal, baseado nos dados registrados de uma amostra de 493 pessoas na cidade de Piracicaba, São Paulo, foi de $98 \%$, enquanto que somente $2 \%$ dos pesquisados revelaram-se vegetarianos.

Deve-se considerar que o número de brasileiros que não consomem produtos de origem animal é bem reduzido. Segundo o IBOPE (2011), $9 \%$ dos brasileiros revelaram-se vegetarianos. Todavia, deve-se considerar que o Brasil tem um consumo per capita de carne bovina, suína e frango importante, 
FRANCHI, G.A. et al. Percepção do mercado consumidor de Piracicaba em relação ao bemestar dos animais de produção. PUBVET, Londrina, V. 6, N. 11, Ed. 198, Art. 1325, 2012.

porém ainda menor do que os países mais ricos do globo. Segundo levantamento realizado pela FAO (2010), o consumo per capita de carne bovina no Brasil é em torno de $31,5 \mathrm{~kg} / \mathrm{ano}$, contra $80,7 \mathrm{~kg} / \mathrm{ano}$ dos países desenvolvidos. Para o frango, o consumo brasileiro gira em torno de 41 kg/pessoa/ano ( $9^{a}$ posição) (USDA/2011). Menor, comparado com outros países como o Kuwait (1 $1^{a}$ posição), maior consumidor de carne de frango, Emirados Árabes Unidos ( $2^{a}$ posição), Hong Kong ( $3^{a}$ posição) e EUA (4a posição) (USDA/2011). No Kuwait, o consumo é de $65,8 \mathrm{~kg} / \mathrm{pessoa} / \mathrm{ano}$ (USDA/2011). Já para a carne suína, o consumo per capita brasileiro é de 14,76 kg (Abipecs/Embrapa/2010), enquanto que em países desenvolvidos, como União Europeia e Hong Kong, o consumo é de $41,8 \mathrm{~kg}$ e 68,6 kg, respectivamente (USDA/Abipecs/2010).

O nível de desinformação da sociedade sobre a temática BEA é evidente por diversas razões. Essas variações vão desde o escasso ensino das escolas e instituições de ensino superior sobre o assunto, até questões religiosas e culturais. Por meio das figuras 3 e 4, é possível analisar essas diferentes realidades.

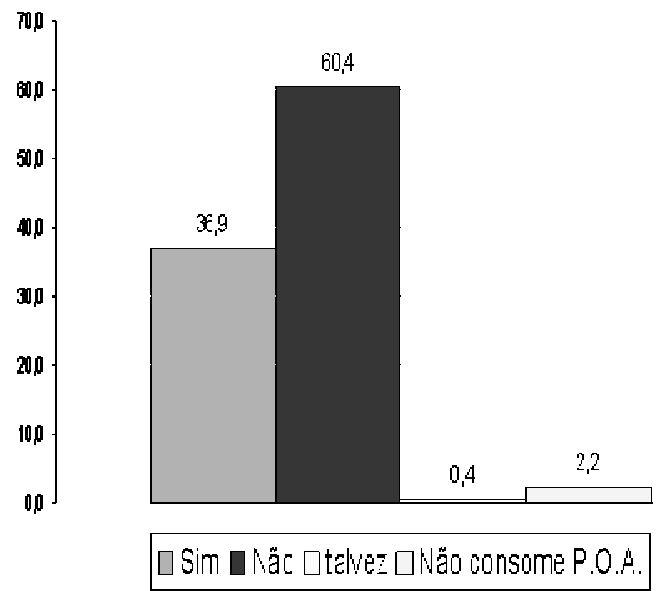

Figura 3: Conhecimento do BEA e tomada de decisão em função do mesmo.

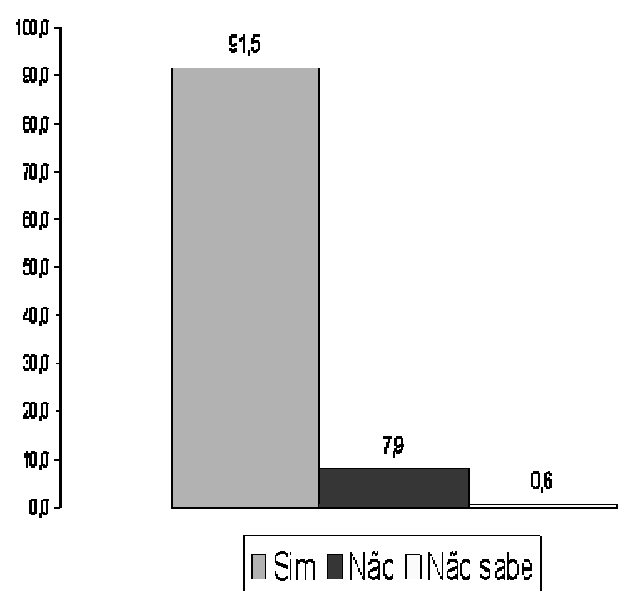

Figura 4: Conhecimento dos entrevistados sobre a sensciência animal.

Mediante análise das figuras 3,4 e 5, é possível avaliar que quase a unanimidade dos entrevistados acredita que os animais possuem sentimentos. 
FRANCHI, G.A. et al. Percepção do mercado consumidor de Piracicaba em relação ao bemestar dos animais de produção. PUBVET, Londrina, V. 6, N. 11, Ed. 198, Art. 1325, 2012.

Contudo, existe um paradoxo, pois mais de $60 \%$ dos entrevistados não leva em consideração o bem-estar dos animais de produção no ato da compra. Contudo, segundo pesquisa levantada pela WSPA/Brasil (2007), com 1000 entrevistados, $73 \%$ dos consumidores concorda com o fato de que comprar produtos oriundos de criações com padrões mais altos de bem-estar animal provocaria um impacto positivo no tratamento de todos os animais de produção. Ou seja, o tema BEA não é um fator de decisão, apesar de que 69 $\%$ dos entrevistados gostariam de aprender mais sobre as condições de vida dos animais de produção no Brasil (WSPA Brasil/2007).

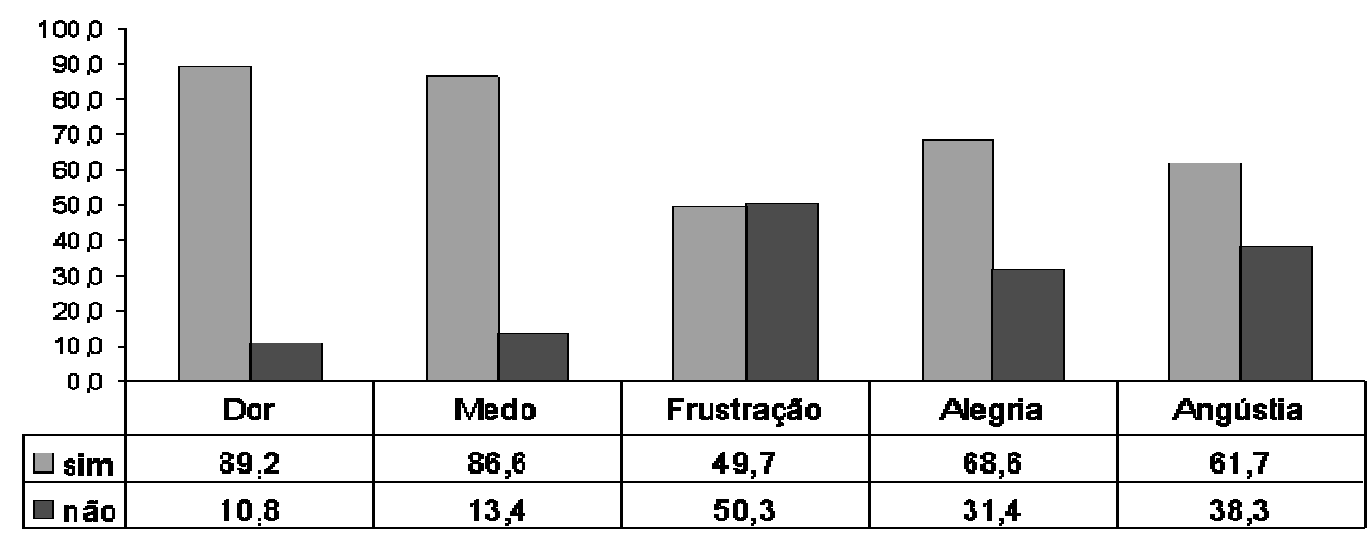

Figura 5: Sentimentos atribuídos aos animais pelos entrevistados

Esses resultados também foram evidenciados no trabalho realizado por Molento et al.(2006), no qual apenas $37,7 \%$ e $27,7 \%$ consideraram sofrimento pequeno para bovinos de leite e galinhas poedeiras, respectivamente. E apenas $31,6 \%, 32,1 \%$ e $35,7 \%$ acreditavam num elevado nível de sofrimento para sistemas de bovinos de corte, frangos de corte e suínos, respectivamente. Tais resultados estão abaixo daqueles encontrados pela WSPA Brasil em 2007, a qual conduziu entrevistas com 1000 brasileiros maiores de 15 anos de idade. Ao fim desse levantamento, constatou-se que $79 \%$ achavam que o tratamento de animais de produção no Brasil é importante, $25 \%$ indicaram que ele é muito importante. Três a cada quatro entrevistados acreditavam que o tratamento dado aos animais de produção no Brasil precisa ser melhorado. 
FRANCHI, G.A. et al. Percepção do mercado consumidor de Piracicaba em relação ao bemestar dos animais de produção. PUBVET, Londrina, V. 6, N. 11, Ed. 198, Art. 1325, 2012.

Também de acordo com a pesquisa da WSPA, $80 \%$ dos consumidores entrevistados acreditavam que os criadores de animais deveriam ser os primeiros a promover melhores padrões de bem-estar animal no Brasil. Sessenta por cento esperava que o governo aprovasse leis para proteger esses animais, $45 \%$ gostaria de ver a indústria de processamento de alimentos promovendo melhores padrões, e 38 \% gostaria que os veterinários fossem os líderes nessa atitude.

Quando se avalia o poder de decisão do consumidor final, faz-se uma análise das características que influenciam diretamente na compra de produtos de origem animal. Por meio da análise da figura 6, é possível observar que as características mais consideradas pelos entrevistados foram a qualidade, o preço e a validade do produto. Houve semelhanças entre os dados dos dois estabelecimentos.

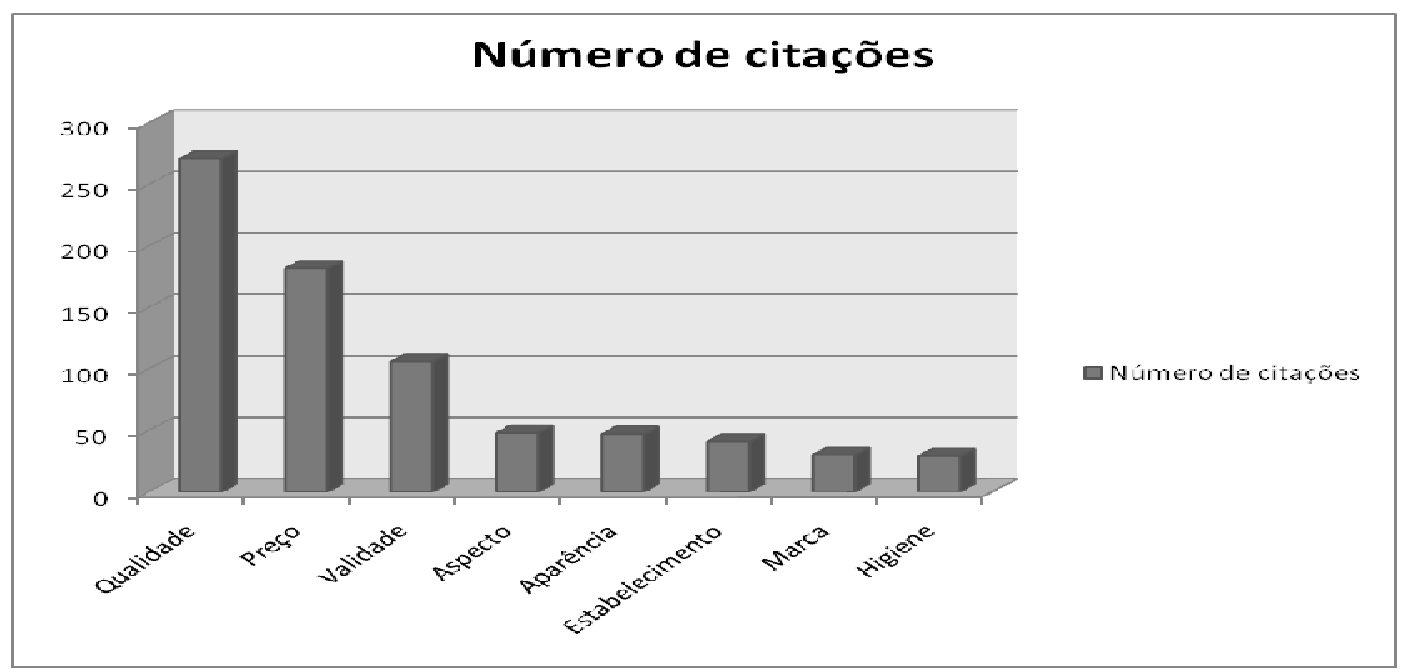

Figura 6: Características consideradas no ato da compra e consumo de produtos de origem animal.

Existe nesse contexto, uma verdadeira desinformação sobre o que realmente é o BEA. Da totalidade de entrevistados, 52\% acreditam que o BEA é um assunto de interesse da sociedade. Porém, como mostrado na figura 3, apenas $36,9 \%$ tem conhecimento sobre o bem-estar dos animais de produção e dizem considerar essas informações na tomada de decisão. Tal fato revela um verdadeiro descompasso entre o que a grande maioria da população pensa 
FRANCHI, G.A. et al. Percepção do mercado consumidor de Piracicaba em relação ao bemestar dos animais de produção. PUBVET, Londrina, V. 6, N. 11, Ed. 198, Art. 1325, 2012.

e o que realmente vem a ser o BEA. De qualquer forma, os resultados apresentados na figura 7 nos revelam a importância do tema BEA para a sociedade.
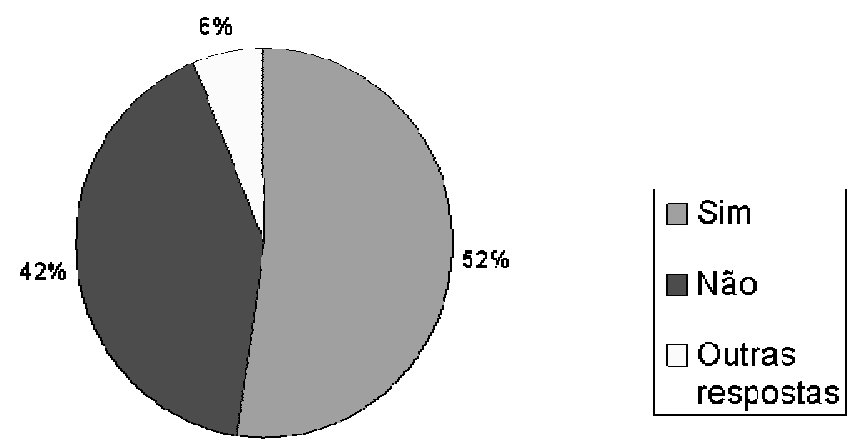

Figura 7: Bem-estar como assunto de interesse da sociedade.

Por fim, a partir dos dados coletados, foi possível comparar e inferir, por meio da figura 8 , até que ponto um valor médio de renda familiar pode influenciar no consumo de produtos de origem animal, na opção pelo BEA, no interesse da sociedade pelo assunto e no reconhecimento da senciência animal pela população.

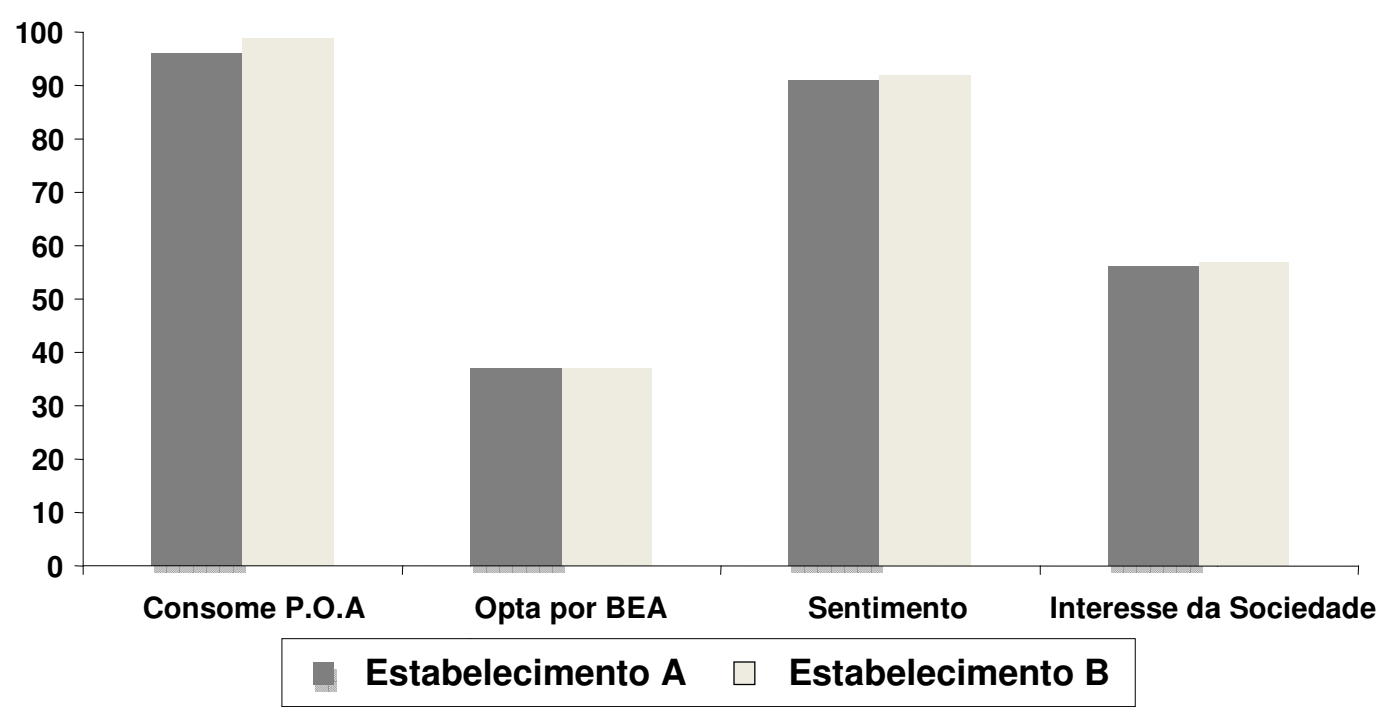

Figura 8 - Renda Familiar (Estabelecimento A $=R \$ 4300,00$ / Estabelecimento $B=R \$ 2000,00$ ) 
FRANCHI, G.A. et al. Percepção do mercado consumidor de Piracicaba em relação ao bemestar dos animais de produção. PUBVET, Londrina, V. 6, N. 11, Ed. 198, Art. 1325, 2012.

Ao se analisar a figura, visualiza-se que em ambas as localidades, os resultados referentes à opção por bem-estar animal, à presença de sentimento pelos animais de produção e ao interesse da sociedade pelo assunto foram semelhantes. E se observarmos minuciosamente, será possível concluir que no estabelecimento $B$, no qual a renda média dos entrevistados era menor, os itens avaliados apresentaram resultados mais satisfatórios do que no estabelecimento A. Revelando-se, portanto, que uma renda menos elevada não foi decisiva para a desinformação do público quanto às maneiras como os animais de produção são criados, manejados e abatidos.

\section{Conclusão}

Ao fim da pesquisa, foi possível levantar as seguintes conclusões:

1. Ao mesmo tempo em que as pessoas consideram a senciência animal, a tomada de decisão quanto ao tema é incipiente.

2. A maior parte, ou $60,4 \%$, dos entrevistados não sabe e/ou não leva em consideração o bem-estar dos animais de produção no ato da compra.

3. As características mais levadas em conta no momento da compra de produtos de origem animal foram: qualidade, preço e validade.

A difusão de conhecimentos com relação ao bem-estar dos animais de produção, bem como sobre questões relacionadas à cadeia produtiva podem contribuir para a preparação da sociedade no sentido do consumo ético. 
FRANCHI, G.A. et al. Percepção do mercado consumidor de Piracicaba em relação ao bemestar dos animais de produção. PUBVET, Londrina, V. 6, N. 11, Ed. 198, Art. 1325, 2012.

\section{Referências}

MOLENTO, C.F.M. Bem-estar e produção animal: aspectos econômicos - Revisão. Arquives of Veterinary Science v.10, n.1, p.1-11, 2005.

W.M. NORDI, D.R. SOARES, E.C. STUPAK, V.G.L. DANTAS, C.F.M. MOLENTO Percepção e atitude em relação ao bem-estar de animais de produção em Curitiba, Ecologia dos Animais Domésticos e Etologia, Departamento de Zootecnia, UFPR, Paraná

LENSINK, B.J., BOISSY, A., VEISSIER, I. The relationship between farmer's attitude and behavior towards calves, and productivity of veal units. Annales de Zootechnie, 43, 313-327, 2000.

BROOM, D.M ; MOLENTO, C.F.M. BEM-ESTAR ANIMAL: Conceito e Questões Relacionadas Revisão (Animal welfare: concept and related issues - Review) Archives of Veterinary Science v. 9, n. 2, p. 1-11, 2004

IBGE 2008

IBOPE 2011

USDA 2011

FAO 2010 - Perspectivas Alimentarias, Análisis de los mercados mundiales

WSPA 2007, Os brasileiros se preocupam com o bem-estar dos animais de produção 